\title{
A new media approach: visualisation of a digital exhibition. Research on representation and design of cultural interfaces
}

\author{
Blanca Acuña \\ Media Lab \\ School of Art and Design \\ Aalto University \\ Hämeentie 153c, FI-00560, Helsinki, Finland \\ bacuna@taik.fi
}

\begin{abstract}
This paper comments on the research project 'A New Media Approach: Visualisation of a Digital Exhibition,' whose final aim is to design a digital interface for a collection of works within the cultural heritage domain of the Xalapa Museum of Anthropology (MAX) in eastern Mexico. This museum hosts a fine collection of about 29,000 Pre-Hispanic pieces of the Olmeca, Central Veracruz and Huaxteca cultures, organises special and theme-based exhibitions, promotes research and publication and acts as a local culture centre. This paper discusses the conceptual framework for the digital interface that will display the most important pieces from the collection at the MAX and reflects on the importance of the strands that feed into the design: interface design, interaction design, information design, information architecture and navigation. The project will explore alternative design solutions of digital interfaces through a triple-interpretation concept, which are: research tool, device of information and learning, and educational resource. Integration of social media tools in the digital interface will also be explored. The project additionally aims to contribute to the analysis of the interaction that takes place when people interact with digital representations and cultural heritage data.
\end{abstract}

Digital exhibition. Digital heritage. Digital tool. Information architecture. Information design. Interaction design. Interface design. Navigation.

\section{INTRODUCTION}

The research project 'A New Media Approach: Visualisation of a Digital Exhibition' is being developed at the Media Lab of the School of Art and Design, in Aalto University, Helsinki, Finland. Its project web site is:

http://mlab.taik.fi/ bacuna/max Project2008/

(Figure 1). The research encompasses the concept and design of a digital interface for the visual display of the most important Pre-Hispanic pieces from the collection of the Xalapa Museum of Anthropology, in Veracruz, Mexico. This museum gathers some of the most important collections from the Olmeca, Huaxteca, and Central Veracruz cultures that developed in the state of Veracruz before the Spaniards' arrival. The complete collection consists of about 29,000 archaeological pieces. Despite the importance of this collection, there is no online digital exhibition for the collected works. Therefore, it is the aim of this project to provide a design to fill this gap with a digital solution.

\section{DIGITAL COLLECTIONS}

Since the 1960s, digitisation activities have pursued the conversion of information from cultural heritage holdings of museums and libraries around the world into digital formats. Many of these initiatives developed by cultural institutions have searched fundamentally for ways to improve the cataloguing of their assets by the use of digital technology (Burton, 2008). However, during the last decades many of these institutions (and other similar types like art galleries) have started to investigate how to design and develop digital applications to enhance their exhibits and collections in newer, interactive and more accessible ways. In addition, current digital heritage projects aim to approach visitors not just onsite an 


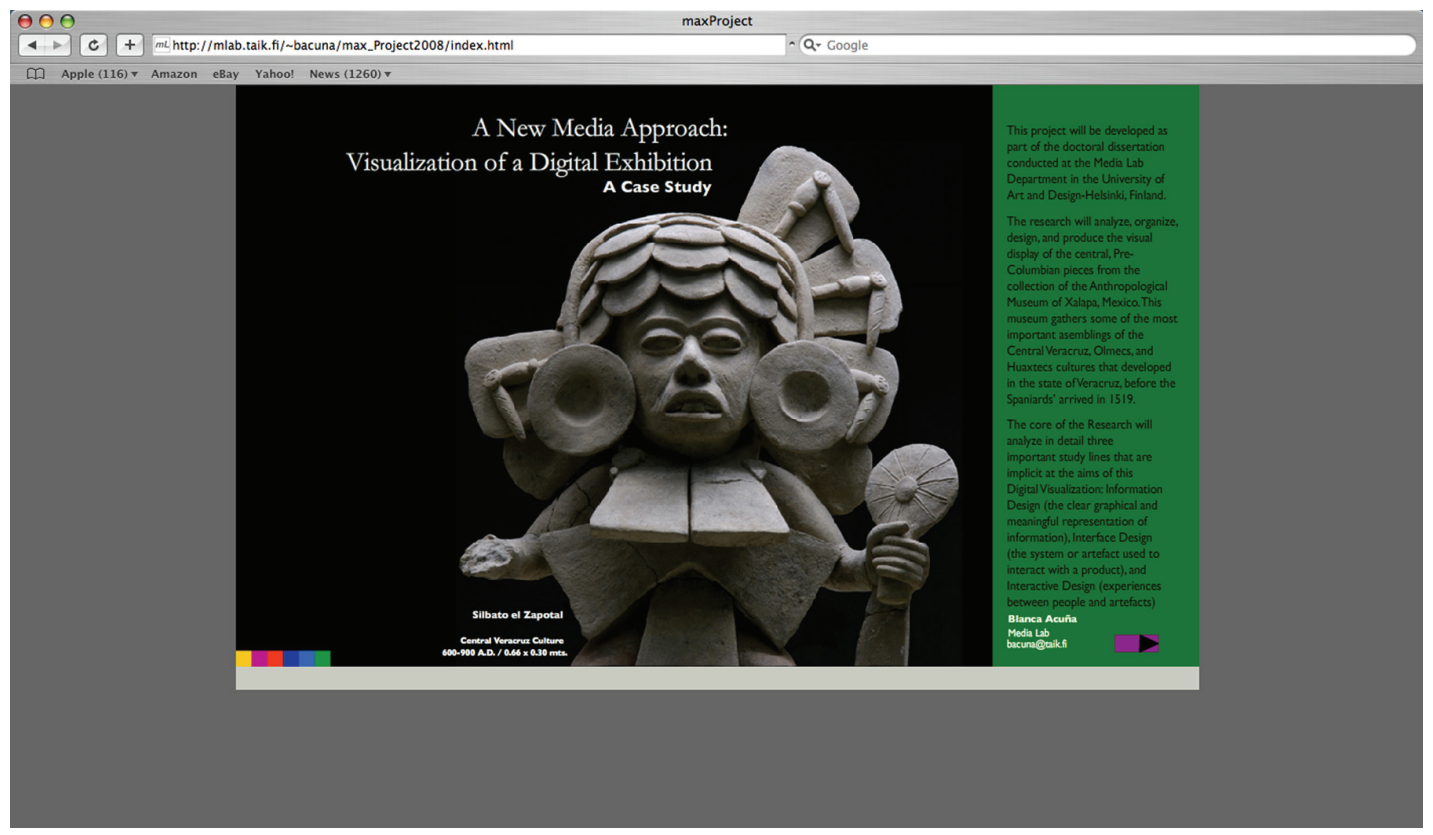

Figure 1: Project website

offline, as it was normal practice within cultural institutions such as museums, but also online and offsite. Parry \& Arbach (2007) have described this as the 'blend of the museum experience.' This fact has been intensified by the current trend in social media and the development of digital tools which support collaboration, social interactions, and community building online.

Consequently, museums have realised that there is a need to incorporate a combination of strategies and planning to enable the implementation of digital schemes such as projects that can not only enhance access to their collections, but that can also contribute to augmenting the transfer of the knowledge embedded in the exhibited artefacts, along with incrementing the exchange of ideas with their communities. This ongoing process of sociotechnical shift encompasses the interactions developed by digital technology, informational resources and people practices, or what has come to be named by some as 'Museum Informatics' (Marty, 2008, p. 3). Likewise, the fusion of these interactions has influenced the model previously followed by most of these institutions of being 'repositories of content' towards a new model of being 'repositories of knowledge' (Marty, 2008, p. 4) that are building open and social environments to explore how to create dialogues with the different communities that want to acquire that knowledge.

This emergent perspective or model is taking advantage of many of the features that digital technology can offer for representation and interpretation of cultural heritage artefacts, for example, the principles of 'modularity', 'variability', and 'transcoding' (Manovich, 2007). The first principle, modularity, is the flexibility of digital elements to be fully or partly integrated into other virtual items without losing their original conformation, so that they can work as modules that can be modified, erased, or subtracted at any time. The second principle, variability, refers to the possibility of producing different digital versions from an original source, and without damaging it. This feature can be produced by the computer system or by the users themselves. The last principle, transcoding, is the capacity to transform a digital element into another format description, which means that transcoding allows having different file types from the same source and with several resolutions. Since it is beyond the scope of this paper to give a comprehensive analysis of digital technology and digital principles, only a few features are commented on to illustrate the discussion.

\section{THE EXHIBITION CONTEXT}

The Xalapa Museum of Anthropology - the MAX, for its Spanish acronym - was established in Xalapa, Mexico, in 1959. It is a museum as well as a research institute belonging to the state of Veracruz and to the Universidad Veracruzana, the state's major university. The MAX holds a very important collection of about 29,000 pieces of Pre-Hispanic origin, including jade masks, clay and stone sculptures, fresco paintings, obsidian and flint arrowheads, copper instruments, ceramics and the 
like. The mission of the Xalapa Museum of Anthropology is to research, restore, guard, display, and disseminate the Pre-Hispanic cultures that established themselves in what is now known as the state of Veracruz (Winfield, 1992).

The modern building of this museum dates from 1986 and covers a total area of 60,000 square meters. A small coniferous forest surrounds it as well as a garden with more than fifty different types of trees and flowers (Winfield, 1992). The museum has twice been given awards: The National Landscape Award by the USA Government in 1992, and The Landscape Architecture Award by the Mexican Landscape Architects Society in 2000 (Arredondo, 2003). The space used for the permanent exhibitions has a total area of 9,000 square meters, divided in eighteen galleries, six halls, four courtyards, one special exhibition hall, a cafeteria, an auditorium and the museum shop. The exhibition halls gather 2,500 pieces from the entire collection of the Pre-Hispanic cultures that settled in the state: the Olmeca culture, Central Veracruz culture and the Huaxteca culture. The exhibition in the museum halls is displayed in chronological order. It starts with the cultures' shaping-period and it finishes with the period previous to the entry of the Spaniards in the current state of Veracruz.

In addition to the mission of restoring and displaying its collection, the Xalapa Museum of Anthropology also coordinates and carries out a range of activities: (1) it organises special and theme-based exhibitions of selected pieces to travel within Mexico and throughout the world; (2) it conducts research and promotes publication about the Pre-Hispanic cultures in the state; (3) it fosters field research in archaeological zones thus aiming at the conservation of the existing monuments and the establishment of excavation sites for new archaeological discoveries; (4) it operates as the location for different types of cultural events such as art exhibits, book presentations, recitals, conferences, and activities for children. Every Sunday the museum organises these activities focused on the Cuates del MAX (The MAX buddies/mates). The idea is to attract children's interest towards the museum collection and archaeological topics.

The informational source for the project 'A New Media Approach: Visualisation of a Digital Exhibition' about the collection and the PreHispanic cultures exhibited in the museum uses resources of different kind and characteristics. First, all the galleries of the museum display labels, maps and info-graphs about the three cultures and some of the most important archaeological pieces, although so far only in the Spanish language. Second, the museum has published books, booklets, and guides that contain photographical records and valuable information, mostly produced by the researchers of the museum. There are also other publications, books as well as magazines about the Pre-Hispanic cultures, produced by independent editors. Third, the museum archive holds the records, photographs and catalogues of the whole of its archaeological collection. In addition to the former sources, there is a stock of high-quality photographs that were developed specially for this project (Figure 2).

\section{DESIGNING AN INTERFACE FOR MUSEUM INTEPRETATION}

\subsection{Framing the design}

The preliminary research done on the literature about the design of digital interfaces, interaction design, information design and museum informatics has incorporated diverse perspectives and knowledge about the development of digital tools and practices for online exhibition. This has also been complemented with the assessment of a number of online projects with special emphasis on the digital heritage domain designed for museums, galleries and cultural institutions. The following section first presents the theories that frame the concept phase of this project, and then the analysis of some online projects in the cultural heritage domain.

The framework for this study is based on three strands which feed into the design of digital applications, aiming to represent and communicate the diverse levels of knowledge embedded in the artefacts of a collection: interface design, which is the system or artefact used to interact with a product; interaction design, which refers to the experiences between people and artefacts, and information design, the clearly graphical and meaningful representation of information (Acuña, 2008). Further relevant concepts are those of information architecture and navigation. The former of these deals with 'mapping out and understanding the connections' (Kolko, 2010, p. 64) of the online space to be designed, while the latter is strongly connected to the way in which a user can go through this designed virtual space by making sense of the mapping.

All the aforementioned disciplines are tightly connected in the practice of creating digital projects. They are in fact so closely intertwined that their elements and structures are needed together to accomplish a comprehensive presentation of online projects. The disciplines converge in the design of the representation of an informationartefact and in the connections and understandings of the diverse meanings of such artefact. When this 


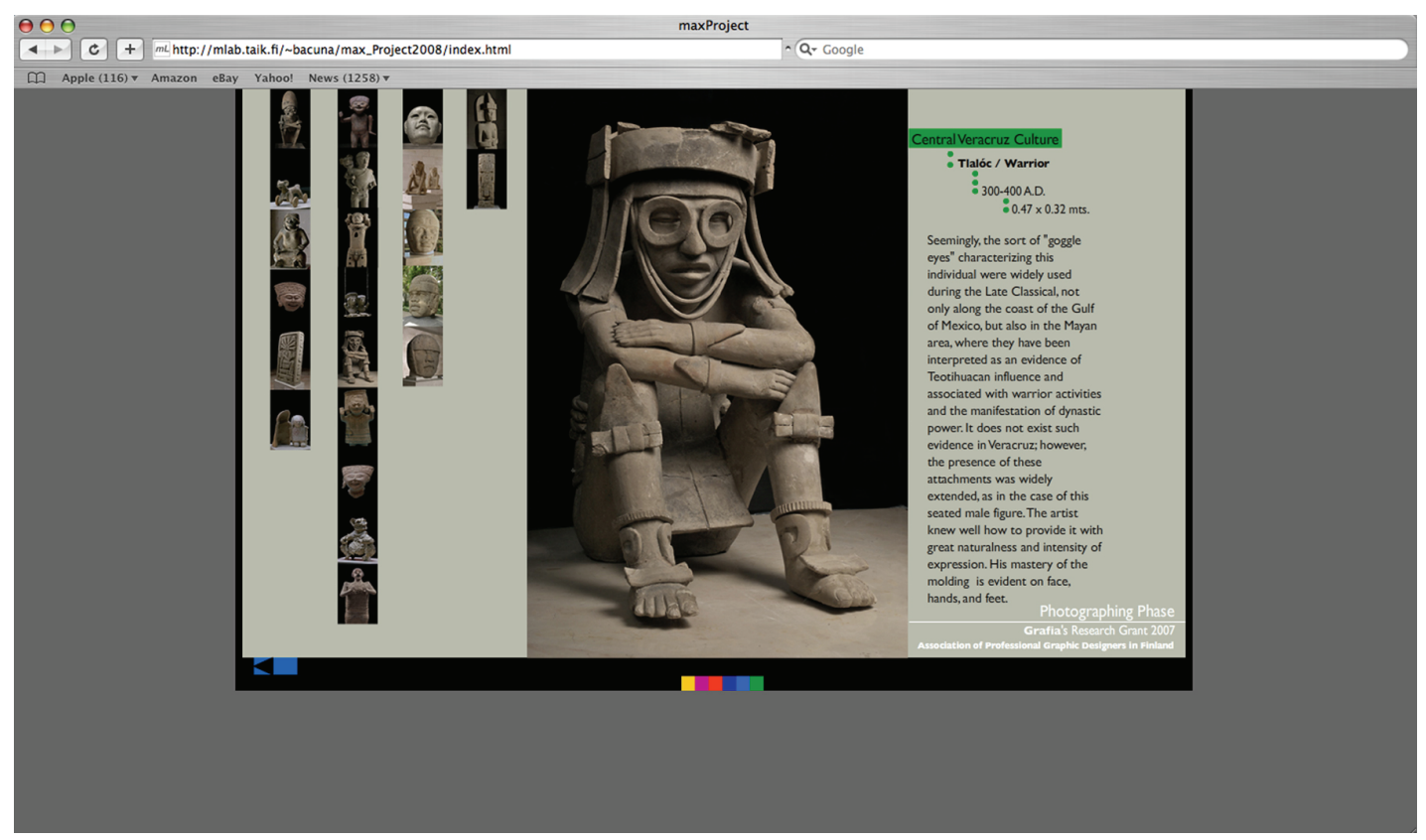

Figure 2: Stock of high quality photographs

Information artefact is placed together with others and relationships between them are formed, then a system of information is created. Developing systems of information is not a straightforward activity. It not only implies the action of producing aesthetical designs of elements, but it also involves contextualising these designs: their aims, their contexts, how others can understand them. Moreover, it is also important to see how the design works when using digital technology, or how it can be transcoded into different types of media, when necessary.

In digital media, an interface has been defined as the point of mediation between users and digital applications (Krippendorff, 2006). An interface can take many shapes, works in different forms and can provide diverse types of interactions depending on its design and goals. It is not only the physical part, but it is also a symbolic aspect, or even a set of instructions such as software: 'We [...] visualize an interface as the place where contact between two entities occurs' (Laurel, 1990, p. xii). The task of designing a digital interface is not only a question of developing physical form solutions. It also involves the creation of visual codes, the selection of hypermedia features and the incorporation of interactive processes that produce actions and responses between the user and the interface. Consequently, the design of an interface is influenced by social and technical factors.

These social and technical factors guide the way in which designers propose a digital interface and the way the interface will work and 'behave'. The discipline that studies this is known as interaction design. Interaction designers analyse the implications of the use of a digital interface, and the possibilities of interaction with it, through the design. In addition, it studies the kind of experiences the interface brings to the users through those interactions.

Different levels of experiences can be achieved by interacting with an interface or with an interactive system. The classification of the levels and its different kinds of experiences receive different names from different scholars: Observation, Exploration, Modification, Reciprocal Change (Meadows, 2003); or the 'Interaction Spectra' consisting of Feedback, Control, Creativity/CoCreativity, Productivity, Communications, Adaptivity (Sheldroff, 1999). In spite of the different names, most of them describe similar characteristics for the interaction process and the types of experiences perceived.

The discipline of information design provides the frame in which context and meaning are given to the visual codes and the visual form of the interface. Information design compositions consist in the harmonic combination of the visual language (through the use of the elements and principles of design) and to a lesser degree of the written language. This evolving blend of languages is creating what Horn describes as the '... functional semantics of visual language' (1999, p. 29), in other words, the creation of systematised 
compositions of clear and balanced units of data designed in such a way that they work as systems of information that can be understood and then converted into knowledge.

Shedroff (1999) illustrates this process of understanding through the steps of data, information, knowledge and wisdom, known as the 'understanding spectrum'. The first step deals with data, the 'raw material' that is gathered, discovered or created. It is the 'factual material derived from observation or measurement' (Peacock 2008, p. $65)$. The second step, information, happens when this data is organised in a visual and meaningful form (for example, graphs, icons, or maps). These 'meaningful forms' disclose the connections among them '... through a human act of meaning making' (Peacock, 2008, p. 65) and consequently they gain the 'value of meaning' and are transformed into information. The third step occurs when information is transformed into knowledge by interacting with the meaningful form of the information. As Shedroff (1999, p. 272) points out: 'It is the understanding gained through experience'. The final step of wisdom, according to the same author, is a kind of 'metaknowledge' that we only obtain at a personal level and is created by reflecting on our own experiences.

Information architecture and navigation are the disciplines that support the connections among the visual elements and mapping of the designed online space. Without their proper application, users would be unable to find and thus make sense of the whole information and meanings that are spread over the online space. They would not be able to know how to find something through the interface or how to get there. Information architecture also helps to organise the planning of a website, since it is used to coordinate in visual form the different parts of that website, as well as the way that these parts will perform.

In regard to the analysis of online projects, it should be noticed that some of them have focused on a rather specific use of digital technology, or that the use of digital tools is aimed mostly at augmenting their collections. Many websites are designed to work as digital exhibitions, repositories of information or learning resources online. While other museums and cultural institutions also have similar online tools, they are at the same time implementing diverse combinations of digital strategies such as social media and usergenerated content. Below are some comments about projects that were analysed.

The Heilbrunn Timeline of Art History, of the Metropolitan Museum of Art, for example, is an online exhibition organised in three branches: geographical, thematic and chronological. It displays the art collection from the Metropolitan Museum of Art and is planned to be accessed by students, scholars and the lay public interested in art history or specific works of art. Another interesting project is the Vincent van Gogh, the Letters, an online parallel project to a book published with the research of the 902 letters that van Gogh wrote or received during his life. It displays the letters in three different languages, with editorial annotations that have hyperlinks referencing to other letters or material, and it is illustrated with the works of art mentioned in the letters. Another project is Search the Collections of the Victoria and Albert Museum. This database holds over a million entries and is constantly being updated. There is also a mobile web interface version of the same database. Recently, this site has also implemented an open 'API' (Application Programming Interface) that can be used by anyone to access the collection of photos and information.

The online collection of the Rijksmuseum of Amsterdam can be sorted via four categories: image, date, artist name and object name. In addition to this, the museum also offers thematic online visits to its collection, for example the Explore 1000 Major Exhibits, where it is possible to see the major exhibits. The section called Masterpieces, provides 3D interactive panoramas of some of the rooms that display the masterpieces. This museum has also implemented the Rijksmuseum widget on desktop and mobile versions; visitors can download any version from the museum's website. Every day, the widget displays a different work of art from the collection. The front area shows the work, and the tool allows one level for zooming in on it. The back part shows the caption in English and Dutch, as well as a link to further information. The widget has an interesting and tidy design.

The last project to be commented on is the Walker Art Center digital project with a wide selection of Web 2.0 applications, including the Art on Call (cell phone audio tours), the Walker Podcasts (iTunes podcasts), and several blogs:

(http://blogs.walkerart.org/), RSS subscription, iCal subscription and the Walker Channel (Webcasts). The institution has also created the ArtConnectED, its online educational section. In ArtConnectED students have access to several educational resources through the use of digital tools such as the Gallery and the Art Collector Tool.

\subsection{Design concept}

The project investigates how to design a digital interface to be used as an interpretation-device by the museum visitors within the digital heritage domain. The design of the digital interface will 
display online the central Pre-Hispanic pieces from the collection of the museum. The interpretative focus of the project will be targeted at three different groups of audience: (a) researchers, academics and higher education students that are investigating these Pre-Hispanic cultures; (b) visitors, young and adult sightseers interested in visiting the museum and learning about the collection; (c) students, children and youngsters that are studying the curricula of these cultures and that form potential groups of visitors to the museum. These three segments of audiences have different agendas and expectations about the museum, as they want to obtain different knowledge and contexts about the exhibited objects. Nevertheless, it should be made clear that these three types of layers are not closed and strict categories but that they may function more as references for framing the project.

The project aims to design alternative solutions of digital interfaces and pathways of access to the collection and its context. It is expected to answer how a digital interface can be designed so as to be used interchangeably as a research support tool, as a device of information and learning on the exhibition, and as an educational resource, how some of the possible layers of representation and interpretation of the cultures can be designed, how to design the interface, so that it could visualise the historical context of the pieces, their uses, and connections in digital format, how to visualise the What?, When?, Who?, and Why? of the three cultures. Finally, the design of the online digital interface will also explore how this interface can be used to enhance the museum visit experience before, during, and after visiting it.

The characteristic of triple-interpretation (research tool, device of information and learning, and educational resource) of the concept will work as layers interfacing the collection. In addition to those, the design will explore other layers that can be constructed around the topic, for instance, timelines, narratives, cosmology, associations, contexts of use and the like. This approach enhances the concept of triple-interpretation of the interface.

In parallel to the above framework, the design of the interface will undertake the incorporation of social media tools as an additional strategy to enhance the communication with the museum's communities. The proposal is to make a selection of social media tools to be used in each of the three concept layers. The selection and level of incorporation of those tools will depend on the analysis of their functionality, as well as on the support that each of them could give to the tripleinterpretation characteristic formerly commented. The approach towards social media will be a complement to the design of the interface, whose implementation aims to illustrate the positive as well as negative implications for the use of such tools within digital cultural heritage projects.

The project is currently in the initial phase of design, parallel to its research stage. So far, there is a website prototype developed in Adobe Flash platform which is regularly updated with the latest adjustments to the design. The online site provides access to a selection of photographs and information of the main archaeological pieces of the museum collection. At present, the information design, information architecture and navigation of the three concept layers are also being worked on. Next on the agenda is the creation of a prototype that displays the triple-interpretation concept and will follow the model of five dimensions proposed by McCurdy et al. (2006). This model encompasses five dimensions that can be used in combination: level of visual refinement, breadth of functionality, depth of functionality, richness of interactivity, richness of data model. The combination of fidelity levels from low to high on prototypes illustrates how effective and scalable (Kolko, 2010) an interface design can be.

\section{CONCLUSION}

The previous discussion illustrates that the design of digital interfaces and systems works within the framework of several disciplines such as information design, interaction design and information architecture, all of which provide concepts that when merged can help us to give visual-shape, actions and meanings to the interface. In addition to the importance of building theory foundations, designers of cultural interfaces also need to consider users' practices with technology so that they can explore how these practices can be adopted into the design of interfaces focused on cultural heritage.

The idea of cultural institutions as repository of knowledge can be augmented by the multiple representational possibilities that hypermedia systems offered. Developing strategies to incorporate social media tools in the design of digital interfaces that are focused on the cultural sector can also round this idea. In the same manner, these strategies may contribute to the building of a more social communication channel between the museum and its different communities.

The ultimate goal of this project is to develop an online digital interface for the MAX that supports research, provides information, and enables easy access to learning resources for the communities interested in this museum. The design of the prototype for this online digital interface draws on 
both the aforementioned theoretical framework and the analysis of a number of digital projects set up by some of the major museums. While the former supports the concept phase of the research project 'A New Media Approach: Visualisation of a Digital Exhibition', the latter contributes to the design of the prototype.

\section{REFERENCES}

Acuña, B. (2008) A new media approach: visualisation of a digital exhibition. A case of study. J. Digital Culture and Electronic Tourism, Vol.1, Nos. 2/3, pp. 253-256.

Arredondo, V. (2003) El Museo de Antropología de Xalapa. In Gobierno del Estado de Veracruz and Gobierno del Estado de Veracruz (eds) Guía oficial Museo de Antropología de Xalapa. Editora del Gobierno del Estado de Veracruz, Xalapa.

Burton, K. J. (2008) The transformation of the Digital Museum. In Marty, P. F. and Burton, K. J. (eds), Museum Informatics: People, information, and technology in museums. Routledge, New York.

Kolko, J. (2010) Thoughts on Interaction Design. Morgan Kaufmann, Burlington, MA.

Krippendorff, K. (2006) The Semantic Turn. A new foundation for design. CRC Press, Boca Raton, Florida.
Laurel, B. (1990) The art of Human-computer Interface Design. Addison-Wesley Publishing, Reading, MA.

Marty, P. F. (2008) An introduction to Museum Informatics. In Marty, P. F. and Burton, K. J. (eds), Museum Informatics: People, information, and technology in museums. Routledge, New York.

McCurdy, M. et al. (2006) Breaking the fidelity barrier. In Proceedings of $\mathrm{CHI} 2006$, Usability Methods. Montreal, Québec, Canada, 22-27 April, pp. 1233-1242. ACM.

Meadows, M. (2003) Pause and Effect: the art of interactive narrative. New Readers, Indianapolis.

Parry, R. and Arbach, N. (2007) Localised, personalised and constructivist: A space for On-line museum learning. In Kenderline, S.. and Cameron, F. (eds), Theorising Digital Cultural Heritage: a critical discourse. MIT Press, Cambridge, MA.

Peacock, D. (2008) The information revolution in museums. In Marty, P. F. and Burton, K. J. (eds), Museum Informatics: People, information, and technology in museums. Routledge, New York.

Shedroff, N. (1999) Information Interaction Design: a unified field theory of design. In Jacobson, R. (ed), Information Design. The MIT Press, MA.

Winfield, F. (1992) Guía oficial. Museo de Antropología. Offset Setenta, Mexico. 